\title{
X-linked adrenal hypoplasia congenita with a novel DAX1 missense mutation
}

Fen-Yu Tseng*, Yu-Ting Tseng, Shyang-Rong Shih, Pei-Lung Chen

Department of Internal Medicine, National Taiwan University Hospital

\section{Introduction:}

$X$-linked adrenal hypoplasia congenita (AHC) is a rare developmental disorder of the adrenal cortex. Adrenal insufficiency typically begins in infancy or in childhood. A few individuals present adrenal insufficiency in adulthood.

\section{Case report:}

The 21-year-old man had underdeveloped secondary sexual characteristics. Physical examination revealed pigmentation over mouth, palmar creases, and joints, small bilateral testes, sparse pubic, axillary hair, and a large arm spanto-height ratio.
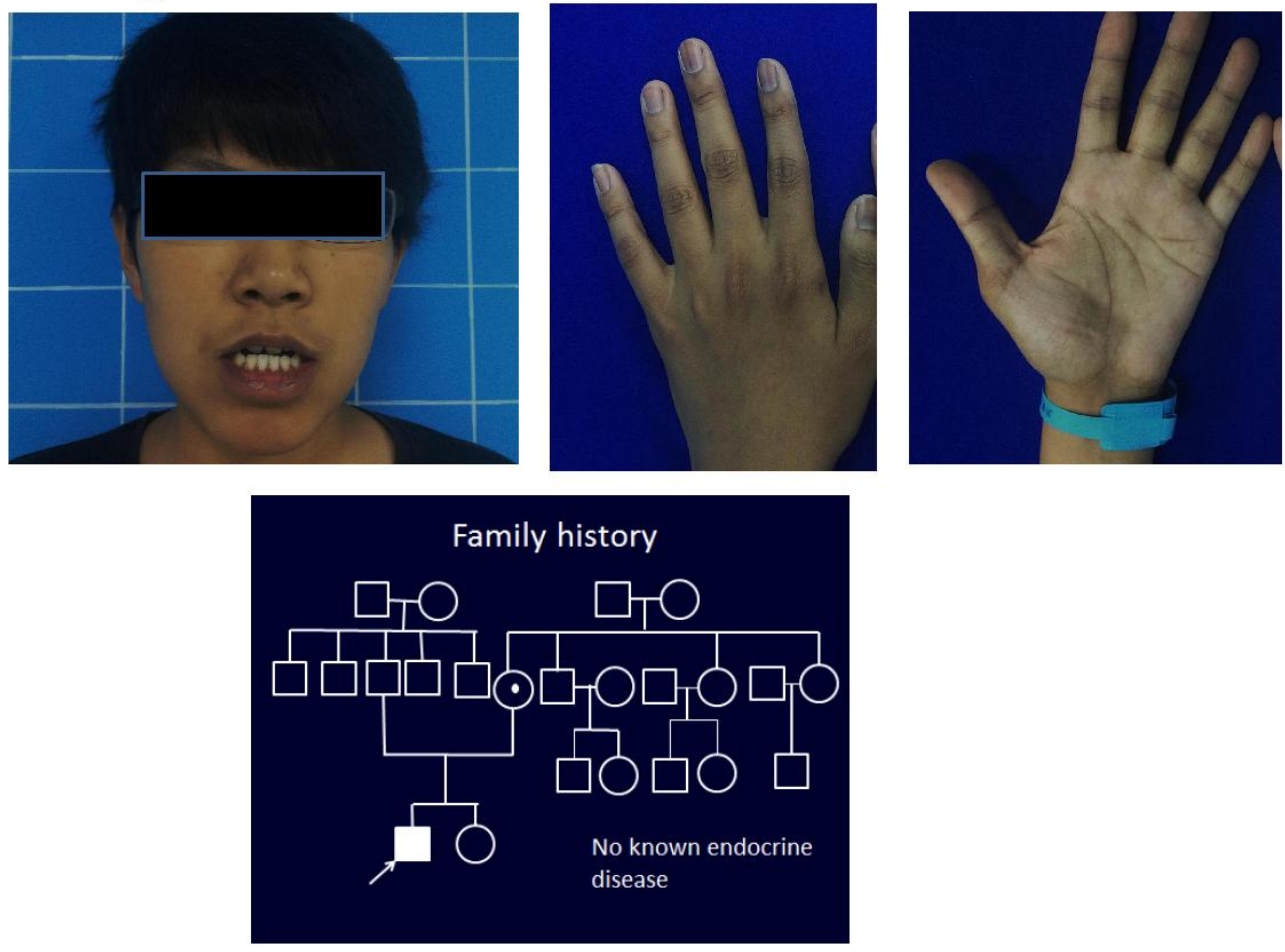

Endocrine function test:

\begin{tabular}{|l|c|c|}
\hline Hormone & Level & Reference \\
\hline IGF-1 $(\mathrm{ng} / \mathrm{mL})$ & 256.2 & $116 \sim 358$ \\
\hline hGH $(\mathrm{ng} / \mathrm{mL})$ & 0.537 & $0 \sim 3$ \\
\hline Prolactin $(\mathrm{ng} / \mathrm{mL})$ & 9.79 & $2.5 \sim 17$ \\
\hline FSH $(\mathrm{mIu} / \mathrm{ml})$ & 4.07 & $0.9 \sim 15$ \\
\hline LH $(\mathrm{mIu} / \mathrm{ml})$ & 2.19 & $1.3 \sim 13$ \\
\hline Testosterone $(\mathrm{ng} / \mathrm{ml})$ & 0.451 & $1.3 \sim 8.1$ \\
\hline DHEA-S $(\mu \mathrm{mol} / \mathrm{L})$ & $<0.41$ & $4.6 \sim 13.4$ \\
\hline Free T4 $(\mathrm{ng} / \mathrm{dL})$ & 1.02 & $0.6 \sim 1.75$ \\
\hline hsTSH $(\mu \mathrm{IU} / \mathrm{mL})$ & 1.74 & $0.10 \sim 4.50$ \\
\hline ACTH $(\mathrm{pg} / \mathrm{mL}) \mathbf{8 m}$ & $>1250$ & $10 \sim 65$ \\
\hline ACTH $(\mathrm{pg} / \mathrm{mL}) 4 \mathrm{pm}$ & $>1250$ & $10 \sim 65$ \\
\hline Cortisol $(\mu \mathrm{g} / \mathrm{dL}) 8 \mathrm{am}$ & 5.37 & $8 \sim 24$ \\
\hline Cortisol $(\mu \mathrm{g} / \mathrm{dL}) 4 \mathrm{pm}$ & 4.07 & $2.5 \sim 12.5$ \\
\hline
\end{tabular}

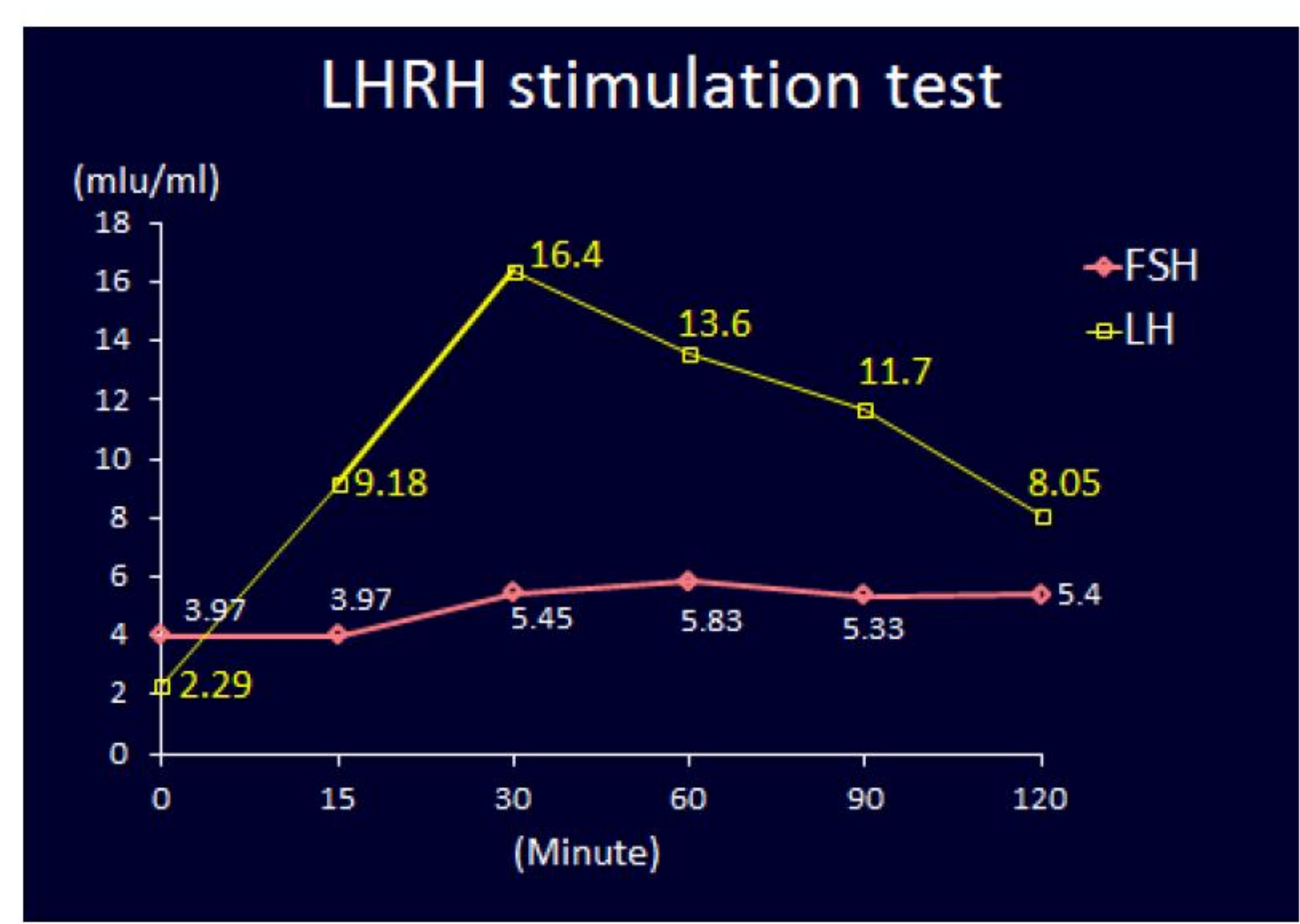

Clomiphene test (50mg BID PO)

\begin{tabular}{|l|c|c|}
\hline & Day 1 & Day 7 \\
\hline FSH $(\mathrm{mIU} / \mathrm{ml})$ & 3.97 & $\mathbf{5 . 9 8}$ \\
\hline LH $(\mathrm{mIU} / \mathrm{ml})$ & $\mathbf{2 . 2 9}$ & $\mathbf{1 . 8 4}$ \\
\hline Testosterone $(\mathrm{ng} / \mathrm{ml})$ & $\mathbf{0 . 4 5}$ & $<\mathbf{0 . 2}$ \\
\hline
\end{tabular}

\section{Abdominal CT and pituitary MRI}

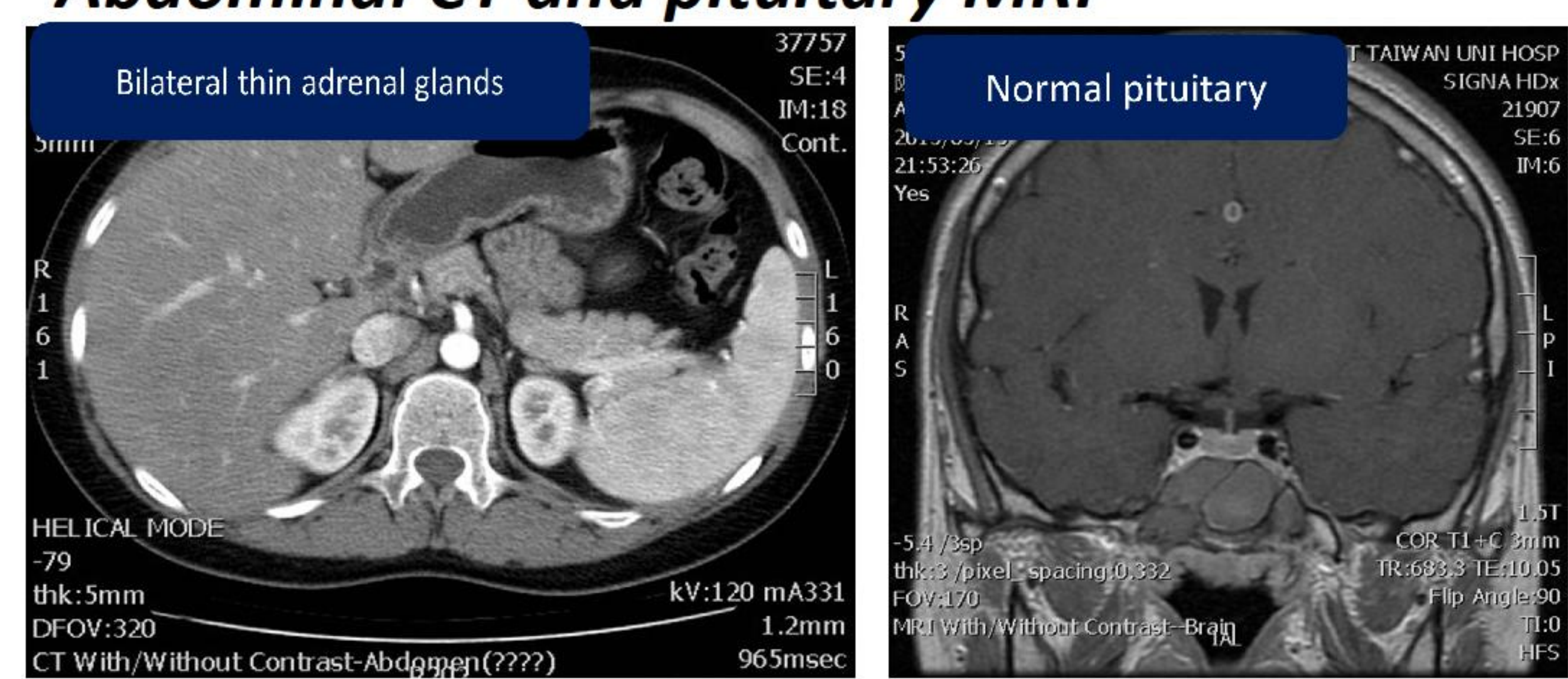

Genetic study

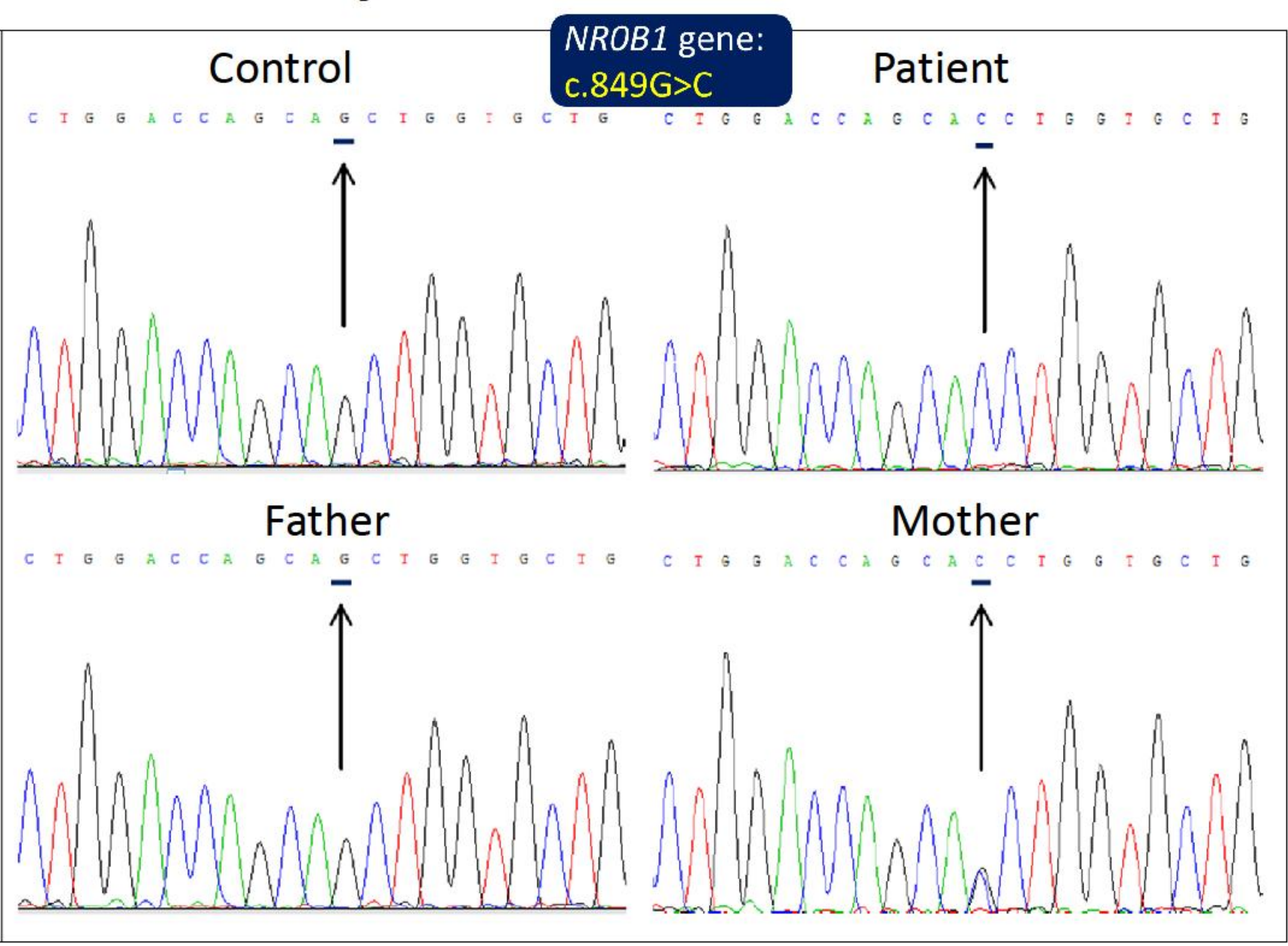

\section{Conclusion:}

DAX-1 gene deletions or mutations have been reported to be responsible for AHC. We report a case of AHC with adult-onset adrenal insufficiency, hypogonadotropic hypogonadism, and a novel missense mutation in the DAX-1 gene. 